Journal Plus Education, ISSN: 1842-077X, E-ISSN (online) 2068-1151 Vol XIX (2018), No. 1. pp. 144-153

\title{
CURVES AND LINES IN STATISTICS - THE IMPLICATIONS OF CURVILINEAR RELATIONSHIP BETWEEN VARIABLES IN A RESEARCH ABOUT THE EFFECTS OF ONLINE FREEDOM OF SPEECH ON VICTIM EMPATHY IN CYBERBULLYING INCIDENTS
}

\author{
Dana BALAS TIMAR, Ph.D. \\ Aurel Vlaicu Universityof Arad, \\ dana@xhouse.ro
}

Abstract: In 2004, Suler referred to the online disinhibition effect, arguing that online environments unleash aspects of individual's personality that normally would have been kept under guard, thus the online hate speech flourishes. Another recent finding gives arguments for the actual detached voyeurs' generation, underlying that by observing on screen, terrible things happening to other people, we develop our own experience towards the victim, but at an emotional distance. The more we observe terrifying events happening to other people, the more they reinforce our sense of denial and detachment, thus resulting a lack of victim empathy. Our research team has developed the project Keeping youth safe from Cyberbullying, ID 2016-3-TR01KA205-036619 aiming to deeper understand the dynamics of different cyberbullying aspects in online environments among youth, by creating an online questionnaire composed by single item research questions related to core concepts and perceptions about cyberbullying motives and effects. Our focus is in analyzing the effects of online freedom of speech agreement on victim empathy in cyberbullying incidents, seen as two core concepts in bystanders' mindset, in 140 high school students. Results show that when modelling effects of online freedom of speech agreement on victim empathy, the curvilinear model (13\%) is more consistent that the linear model (9\%), even if both models show statistical significance. Psychological and methodological conclusions and implications are discussed.

Key words: cyberbullying; perceived online freedom of speech; victim empathy; curvilinear relationship; 


\section{Introduction}

Without freedom of expression there is no exchange of ideas, there is no public debate, there is no possibility to be informed, to choose or to express ourselves artistically. Our everyday choices, the way we dress, the music we are listening to, the books we read, the media we are informing about, are all expressions of the right to freely express. Freedom of expression, a major topic of interest for the European Court of Human Rights in recent times, has earned new valences. As stipulated, the moderator of an internet forum cannot be held accountable to the court for injurious or rude comments, if they do not contain a hate speech or a call to violence, thus ECHR "revolutionizing" the freedom of expression in the online environment.

There are hundreds of millions of content creators and recipients over the Internet. They are present on blogs, forums, social networks and various other online communities. Both categories exercise, in different ways but from positions of total legal equality, the right to free expression. This freedom, however, has the same limitations as for any other media. Everyone has the right to free speech, but within certain limits. Freedom of expression consists of thoughts, ideas, opinions, beliefs, creations, but also in tastes, habits and options, affirmed without any constraints and limitations, in public. Generically it implies both acts of speech and writing, as well as acts of affirmative or negative conduct. Expression can be accomplished in speech, in writing, through images and sounds, or by mimics and gestures. The environments in which we express ourselves are either offline or online publications, public space in a physical sense, and any other means of communication in public, including electronic media. Anonymity can better secure privacy and, at the same time, enhance freedom of speech, especially over the Internet, where the anonymity of the presence of people stimulates the formulation of useful opinions and comments, but which can often be so challenging that, in the absence of anonymity, their author would be discouraged from expressing them. Obviously, the condition of legality is that its anonymity does not by itself become a threat to the privacy of others, as well as others' values protected by society. In conclusion, freedom of expression is guaranteed, but it must not be understood in an absolute way, not even over the Internet.

Our approach is centered on the answer to when does freedom of speech turn into cyberbullying. Recent statistics prove a disastrous picture of this threshold being exceeded. According to the Cyberbullying Research Center: over 80 percent of teens use a cell phone regularly, making it the most popular form of technology and a common medium for cyberbullying; about half of young people have experienced some form of cyberbullying, and 10 to 20 percent experience it regularly; mean, hurtful comments and 
spreading rumors are the most common type of cyberbullying; girls are at least as likely as boys to be cyberbullies or their victims; boys are more likely to be threatened by cyberbullies than girls; cyberbullying affects all races; cyberbullying victims are more likely to have low self-esteem and to consider suicide; cyberbullying is the biggest part of 4500 teen suicides.

Essentially, cyberbullying represents a repeated, intentional act of aggression mediated through some form of electronic contact. Researchers estimates that many of these adolescents that become victims of cyberbullying suffer from reduced self-esteem and depression as a result. Taken to a higher level, besides direct victimization, $70 \%$ of internet users have up to a point witnessed some form of online harassment. Research concludes that even if data show a high percentage of bystanders, persons who could potentially stop the online harassment, in most of the cases these witnesses remain idle, silent about the event that took place before their eyes.

Scientific literature consistently reports that people rarely intervene in bullying incidents, particularly online due to the bystander effect, a social behavior phenomenon first identified by social psychologists John Darley and Bibb Latané in the late 60s and early 70s (Darley, \& Latané, 1968, 1970). Authors found that most people who witness an emergency do not assist when there are other witnesses, or bystanders, to the event, refraining from helping because of the belief that another bystander will eventually interfere and act. Alternatively, if no one takes action and helps the victim, bystanders assume that the norm is to not act, thus to not help.

When moving the theory into the online setting, nowadays research conclusions underline that while the Internet makes communication much easier, it doesn't necessarily make bystander intervention more likely. Even if myriad of bystanders can see an aggressive post or a request for help, few people actually respond. This fact can be explained by the bystander effect, stating that witnesses will immediately assume that someone else will act, or other people have already responded. Online witnesses are less likely to intervene due to the psychologically separation in terms of physical distance and time of occurrence of the aggressive event, thus the spatial and temporal distance offers bystanders reasons to believe that means that there's nothing to be done to help stop online aggression. None of the less, if the internet provides few options for adults to stop the aggression, for youth this process is even more difficult. It is well known the fact that youth are in generally unwilling to tell responsible adults about cyberbullying incidents, because of different types of fear most of them related to shame, becoming a target themselves, internet browsing deprivation and many others.

As a general conclusion, most research found that bystanders become active in reporting cyberbullying incidents when they empathize with the victim. A lot of prevention programs regard youth empathetic training 
through role plays and theatre forums presenting different real cases of youth being online psychologically abused, with the purpose of raising empathetic responses towards the victim.

\section{Research methodology}

The Erasmus project Keeping youth safe from Cyberbullying, ID 20163-TR01-KA205-036619, was developed by our research team, with the purpose of deeper understand the dynamics of cyberbullying in online environments among youth. Among the first research questions purposed by our team was the identification of the existent relationship between online freedom of speech and victim empathy in cyberbullying. In this regard, we have designed an online questionnaire aiming to gather descriptive data, general perceptions about cyberbullying phenomenon and perceptions about the safety of the educational environment, bystander motives of keeping silent, perceived parental support, and an auto evaluation scale centered on self-efficacy perceptions.

One of our initial interests was in analyzing the relationship between perceptions about online freedom of speech and victim empathy in cyberbullying type incidents, due to the fact that we consider the perceptions youth have about the online freedom of speech impact the amount of emotional investment in empathy towards a victim of online psychological abuse.

Present study takes position that single item measures owns the same efficacy in identifying statistical trends like multiple items scales, regarding online measuring of youth perceptions. Single item measures have been previously successfully used by researchers when measuring for example quality of life (Zimmerman et al., 2006). Single item scales are usually used to represent global constructs (Wanous, Reichers, Hudy, 1997) that are conceptualized as mono facet or dimensions, like the ones we have focused on, online freedom of speech and victim empathy.

The two items that measure online freedom of speech and victim empathy:

Item A6 - Please rate your opinion regarding the following affirmation: I have the right to say online anything I want, even if my words hurt somebody.

\section{Totally agree.}

2. Agree.

3. Neutral.

4. Disagree.

5. Totally disagree.

Item $\mathbf{8}$ - What do you feel about victims in online harassment?

a. They deserve it. 


\section{b. I am sorry, but there is nothing I can do about it. c. That is a serious problem we have to stop.}

Our hypothesis states that two research variables: online freedom of speech and victim empathy are in a curvilinear relationship. In order to test our curvilinear hypothesis, we have used SPSS' multiple linear regression analysis, based on multiple regression analysis for curvilinear effects, where victim empathy was the dependent variable.

The study was conducted on a random sample of 140 high school students aged 17-19, of both sexes, 68 males (48.6\%) and 72 females $(51.4 \%)$, from both rural and urban environmental origins.

\section{Results}

In order to test our hypothesis that states that between online freedom of speech and victim empathy there is a curvilinear relationship, we have used a confirmatory factor analysis, based on multiple regression analysis for curvilinear effects.

A curvilinear relationship is described as a relationship between two or more variables which can be graphically depicted by anything other than a straight line. A particular case of curvilinear relationships is the situation where two variables grow together until they reach a certain point (positive relationship) and then one of them increases while the other decreases (negative relationship) or vice-versa, the graphically representation of the function being an $U$ or an inverted $U$ shape.

This relationship can be easily identified graphically by a Scatterplot, choosing additional two representations of the regression line: Linear and Quadratic model, for depicting curvilinear effects. The Scatterplot diagram presented in Figure 1, indicates the curvilinear relationship between online freedom of speech on the horizontal axis and victim empathy, represented on the vertical axis. The sample consists of 140 youth from Arad, Romania. 


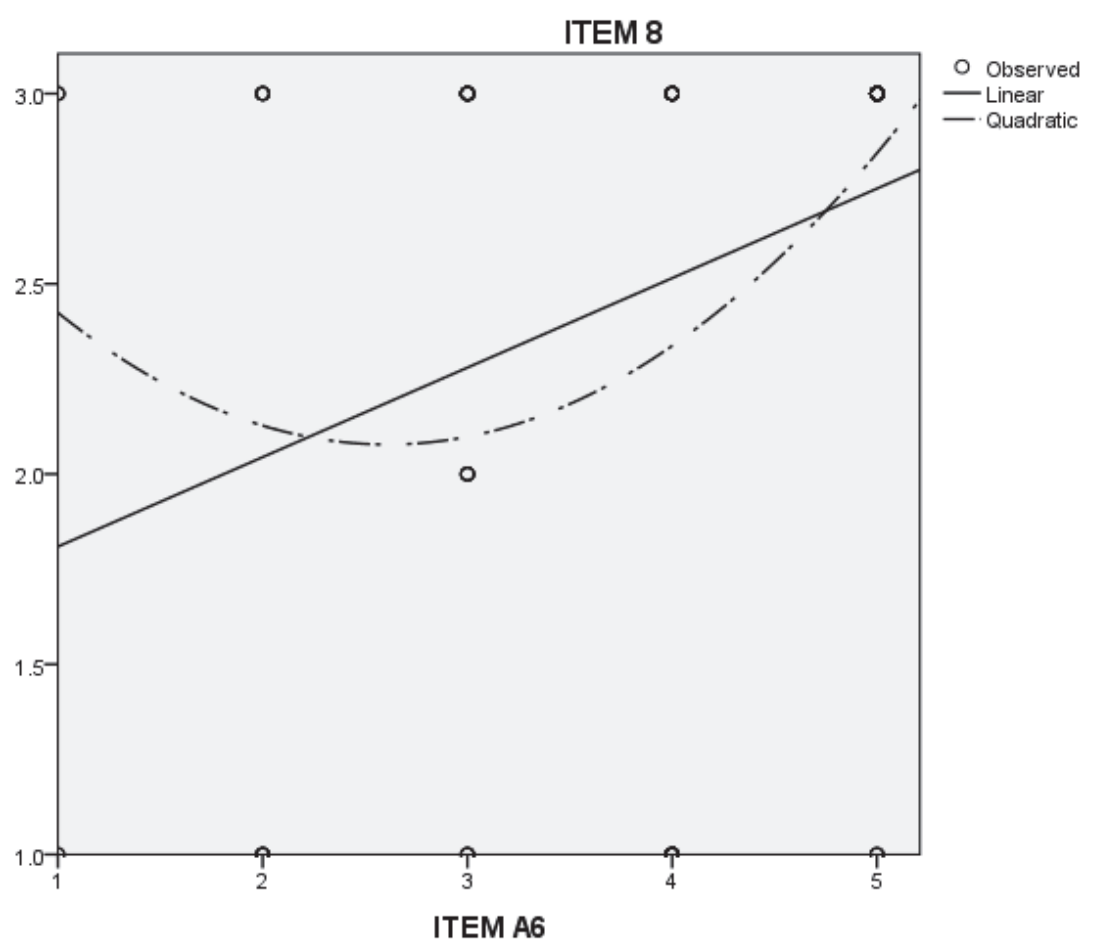

Fig. 1. The curvilinear relationship between online freedom of speech (Item A6) and victim empathy (Item 8)

There is a very high correlation between online freedom of speech perceptions - Item A6 $(\mathrm{m}=4.06, \mathrm{SD}=1.13)$ and victim empathy - Item 8 $(\mathrm{m}=2.53, \mathrm{SD}=0.83)$ of $r=.318$ significant at a $\mathrm{p}<.01$ which methodologically allows us to proceed with multiple linear regression analysis.

For curvilinear relationship testing, the present study proposes a hierarchical multiple regression analysis, the dependent variable being victim empathy (Item 8), and the independent variable in step 1 online freedom of speech (Item A6), and instep 2 online freedom of speech (Item A6), and squared online freedom of speech (sqrtA6).

Table 1 presents the fitting of the two models, linear - Model 1 and curvilinear/ quadratic - Model 2. As we can see in Model 1 the model that supposes linear relationship, victim empathy accounts for $9 \%$ of the variance in online freedom of speech with an $F=15.579$ significant at a $\mathrm{p}<.01$. In Model 2, the model that supposes curvilinear relationship, victim empathy accounts for $13 \%$ of the variance in online freedom of speech with an $F=11.780$ significant at a $p<.001$. 
Table 1. Linear and curvilinear regression models for freedom of speech (Item A6) and victim empathy (Item 8)

Model Summary

\begin{tabular}{|l|r|r|r|r|}
\hline $\begin{array}{l}\text { Mode } \\
1\end{array}$ & R & R Square & $\begin{array}{c}\text { Adjusted R } \\
\text { Square }\end{array}$ & $\begin{array}{r}\text { Std. Error of } \\
\text { the Estimate }\end{array}$ \\
\hline 1 & $.318^{\mathrm{a}}$ & .101 & .095 & .794 \\
2 & $.383^{\mathrm{b}}$ & .147 & .134 & .777 \\
\hline
\end{tabular}

a. Predictors: (Constant), Item A6.

b. Predictors: (Constant), Item A6., sqrtA6

\begin{tabular}{|rl|r|r|r|r|r|}
\hline \multicolumn{1}{|c|}{ MNOdel $^{\text {M }}$} & & Sum of Squares & df & Mean Square & F & Sig. \\
\hline \multirow{2}{*}{1} & Regression & 9.828 & 1 & 9.828 & 15.579 & $.000^{\mathrm{b}}$ \\
& Residual & 87.058 & 138 & .631 & & \\
& Total & 96.886 & 139 & & & \\
& Regression & 14.216 & 2 & 7.108 & 11.780 & $.000^{\mathrm{c}}$ \\
2 & Residual & 82.669 & 137 & .603 & & \\
& Total & 96.886 & 139 & & & \\
\hline
\end{tabular}

a. Dependent Variable: Item 8

b. Predictors: (Constant), Item A6

c. Predictors: (Constant), Item A6, sqrtA6

\begin{tabular}{|c|c|c|c|c|c|}
\hline \multicolumn{6}{|c|}{ Coefficients $^{\mathrm{a}}$} \\
\hline \multirow[t]{2}{*}{ Model } & \multicolumn{2}{|c|}{ Unstandardized Coefficients } & \multirow{2}{*}{$\begin{array}{c}\begin{array}{c}\text { Standardized } \\
\text { Coefficients }\end{array} \\
\text { Beta }\end{array}$} & \multirow[t]{2}{*}{$\mathrm{t}$} & \multirow[t]{2}{*}{ Sig. } \\
\hline & B & Std. Error & & & \\
\hline (Constant) & 1.574 & .251 & & 6.271 & .000 \\
\hline Item A6 & .235 & .060 & .318 & 3.947 & .000 \\
\hline (Constant) & 2.989 & .579 & & 5.160 & .000 \\
\hline Item A6 & -.699 & .351 & -.946 & -1.989 & .049 \\
\hline sqrtA6 & .134 & .050 & 1.282 & 2.697 & .008 \\
\hline
\end{tabular}


Legend - Original romanian questions:

Item 8. Question: Ce simțiți în legătură cu persoanele agresate în mediul online? Answer: a. O merită (code 2), b. Îmi pare rău, dar nu am ce să fac în legătură cu asta (code 1), c. Este o problemă serioasă, pe care trebuie să o stopăm (code 3$)$

Item A6. Question: Vă rugăm să vă exprimați părerea cu privire la următoarea afirmație: A6. Am dreptul sa spun ce vreau online, chiar daca cuvintele mele ii ranesc pe ceilalti. Answer: a. Acord total (1), Acord (2), Neutru (3), Dezacord (4), Dezacord total (5)

All standardized coefficients of Beta $(\beta=.318 ; \beta=-.946$ and $\beta=1.282)$ are significant at $p<.05$ which gives a high consistency to our both models. Changing Beta coefficient's sign from + to - means that the effect is growing in the opposite direction, which demonstrates that the relationship between the two variables: online freedom of speech and victim empathy is not linear, but curvilinear. The additional incremental predictive capacity of 4 percent, added by including the squared online freedom of speech variable which is accounting for the band in the regression line, indicates that there is a curvilinear relationship between online freedom of speech and victim empathy.

This curvilinear relationship demonstrates that extreme aspects, extremely reduced and extremely high levels of agreement to online freedom of speech regardless of consequences, significantly influences the activation of victim empathy type of response, meaning that the participants to an online aggression will feel empathy towards the victim, while situating on the neutral segment of agreement to online freedom of speech, triggers the non-empathetic response towards the victim in a cyberbullying event.

Until now, we are not aware of any research indicating a curvilinear relationship between online freedom of speech agreement and victim empathy, thus, this study may help expanding the current body of knowledge on psychological aspects of triggering empathetic responds towards the victims in online aggressions.

\section{Conclusions and implications}

As underlined by the scientific literature, empathic training concern is the most important predictor of the abuse report behavior, youth characterized by high levels of empathic concern were more likely to help victims of cyberbullying. As described by the bystander effect, in a cyberbullying event, the non-active behavior is often reinforced by 
bystanders who consent approve their acts by not reporting the incident, thus not helping the victim. Such conclusions explain why intervention programs targeting the behavioral change of bystanders' prove to be effective in reducing bullying (Polanin, Espelage, Pigott, 2012; Salmivalli, Kärnä, Poskiparta, 2011). Only recently, cyberbullying researchers have started to explore the determinants of bystanders' reactive behaviors (Barlińska, Szuster, Winiewski, 2013; Freis, Gurung, 2013; Li, Fung, 2012; Macháčková, Dedkova, Sevcikova, Cerna, 2013). Bystanders demonstrated more defending behaviors in the absence of other bystanders, thereby validating the bystander effect in cyberbullying situations; also low moral disengagement, low anti-social conformity, high perceived control of the situation and bad relationship with bullies were identified as significant predictors of a bystander's defending tendency (Song, Oh, 2018).

The social conclusion of this research is that cyberbullying risk is the dark side of online free speech. As technology continues to outgrow and become an important tool in everyday communication, societies have to invest more interest in protecting youth from the impacts of hurtful and threatening communication and protecting in the same time the youth online freedom of speech. Is well known the fact that harassment owns the effect of silencing free speech, but as a democratic society responding to censorship with more censorship does not represent a mature answer. Rather than silencing even more the youth freedom of speech that does not represent cyberbullying, societies should approach the subject with creativity, compassion and empathy.

\section{References:}

Barlińska, J., Szuster, A., Winiewski, M. (2013). Cyberbullying among adolescent bystanders: Role of the communication medium, form of violence, and empathy. Journal of Community \& Applied Social Psychology, 23(1), 37-51.

Darley, J.M. \& Latané, B. (1968). Bystander intervention in emergencies: Diffusion of responsibility. Journal of Personality and Social Psychology. 8: 377-383.

Darley, J.M., \& Latane, B. (1970). The unresponsive bystander: why doesn't he help? New York, NY: Appleton Century Crofts.

Freis, S.D., Gurung, R.A. (2013). A Facebook analysis of helping behavior in online bullying. Psychology of Popular Media Culture, 2(1), 11-19.

Li, Q., \& Fung, T. (2012). Predicting student behaviors: Cyberbullies, cybervictims, and bystanders. In Q. Li, D. Cross \& P. K. Smith (Eds.), Cyberbullying in the global playground: Research from international perspectives (pp. 99-114). Oxford, England: Wiley-Blackwell. 
Journal Plus Education, ISSN: 1842-077X, E-ISSN (online) 2068-1151 Vol XIX (2018), No. 1. pp. 144-153

Machackova, H., Dedkova, L., Sevcikova, A., \& Cerna, A. (2013). Bystanders' support of cyberbullied schoolmates. Journal of Community and Applied Social Psychology, 23, 2536. http://dx.doi.org/10.1002/casp.2135

Polanin, J.R., Espelage, D.L., Pigott, T.D. (2012). A meta-analysis of schoolbased bullying prevention programs' effects on bystander intervention behavior. School Psychology Review, 41, 47-65.

Salmivalli, Christina, Antti Kärnä, and Elisa Poskiparta. (2011). Counteracting Bullying in Finland: The KiVa Program and Its Effects on Different Forms of Being Bullied. International Journal of Behavioral Development 35:405-11.

Song, J. \& Oh, I. (2018). Factors influencing bystanders' behavioral reactions in cyberbullying situations. Journal Computers in Human Behavior, Volume 78, Issue C, 273-282.

Suler, J. (2004). The Online Disinhibition Effect. CyberPsychology \& Behavior, 7(3), pp.321-326.

Wanous, J.P., Reichers, A.E., Hudy, M. J. (1997). Overall job satisfaction: How good are single-item measures? Journal of Applied Psychology, 82, 247-252.

Zimmerman, M., Ruggero, C.J., Chelminski, I., Young, D., Posternak, M.A., Friedman, M., Boerescu, D., Attiullah, N. (2006). Developing brief scales for use in clinical practice: the reliability and validity of single-item selfreport measures of depression symptom severity, psychosocial impairment due to depression, and quality of life. J Clin Psychiatry, 67(10), 15361541 . 